The Geneva Papers on Risk and Insurance, 23 (No. 87, April 1998), 196-209

\title{
Asymmetric Information, Moral Hazard and the Insurance of Legal Expenses*
}

\author{
by Roger Bowles** and Neil Rickman***
}

\section{Introduction}

In many countries there are both private and social insurance arrangements to help consumers meet the irregular but substantial costs of employing lawyers. Some of these schemes are well established and work smoothly, but others have had a less comfortable experience and some of the arrangements work rather poorly. The markets are sometimes thin, the exclusions from policies substantial and the costs of meeting claims difficult for insurers to contain: Insurance Trends (1997). These barriers to smooth functioning are often the result of standard sorts of moral hazard and adverse selection problems. But some of the barriers are attributable to agency problems arising within the insurer-lawyer relationship. Recent developments in the economic analysis of asymmetric information provide a useful means for exploring the structure of insurer-provider contracts, and we set out here to show how some of the theoretical advances can be applied to markets for legal services. In particular we consider the insurer-lawyer relationship in the broader setting of a three-way relationship between the insurer, the lawyer and the client. This approach provides a natural base from which to make a comparison between the private and social provision of insurance of the costs of legal expenses and also to evaluate some recent policy proposals in the UK.

* Paper prepared for: Joint Conference of European Association of Law and Economics and the Geneva Association, Hamburg, 7-8 April, 1997. We are grateful to conference participants for comments on an earlier draft.

** School of Social Sciences, University of Bath, Bath BA2 7AY, UK.

*** Department of Economics, University of Surrey, Guildford GU2 5XH, UK. 
The purpose of this paper is to make a comparison between the private and social insurance of legal expenses in the UK and to relate developments in these two sectors with analytical and policy issues arising in other spheres in which professional services are delivered via a mixture of private and social insurance institutions. We show that parallels with the provision of health care in the US, and recently in the UK, can illuminate some of the issues facing private and social insurers alike. We argue also that the UK government's proposal to move to a system of "bulk contracts" for the provision of publicly-subsidized legal services can be interpreted as an effort to counter the significant agency problems arising within the social insurer-private provider setting of the present Legal Aid system.

To begin a framework must be established, within which the social and private insurance of legal expenses can be located. This framework is intended to be sufficiently general to encompass not only the comparison of social and private insurance provision but also to help identify the key issues confronted by insurers and to enable comparisons with the operation of other markets for comparable services.

\section{The Insurance of legal expenses}

The unpredictability of legal costs makes them a potential target for insurers. But there are at least three factors inhibiting the development of insurance, namely:

- a person holding legal expenses insurance (LEI) may be much more likely to initiate a legal action than an uninsured person;

- the intensity with which the policyholder (or socially insured citizen) will wish to pursue a claim once it has been initiated may be much greater than the intensity a self-financing person would choose; and:

- the propensity of an individual to buy insurance against legal expenses may be significantly higher if they have characteristics and/or preferences which make them more likely than others to bring a legal claim.

Despite these inhibitions, many countries have developed institutions which provide some degree of insurance against legal costs. General household savings to cover the contingencies of life may be used sometimes by citizens to finance the early stages of a legal action. But for lower income groups particularly it is unlikely that private savings will be on the kind of scale needed to fund an action to recover damages for personal injury, say, or to contest a probate decision. Other institutions fill some of the gap which remains. Employee organizations such as Trade Unions may offer their members support for bringing certain sorts of legal claims. But this still leaves plenty of scope for individuals to find themselves in a position where they are prepared to contribute to either (or both) a private LEI scheme and via taxes to a social insurance scheme. We consider these two alternatives briefly.

\subsection{Social Insurance}

In most countries at least some legal services are provided to citizens at the expense of the state. The method of service provision and of service financing varies widely. Some countries use a "public defender" system in which lawyers are directly employed by the 
state to provide legal services to citizens who qualify on grounds of "legal need", financial hardship or whatever. Other countries rely on a regulatory requirement that trainee lawyers, or those who have recently qualified, take on a minimum number of "pro bono" cases for nominal fees: for a review of practices see Skordaki and Walker (1994). Yet other countries, and in particular the UK, rely on a system in which qualifying citizens receive legal services from private law firms who are then reimbursed through a government agency, according to some preset schedule of fees (including hourly rates and fee for service items), for the work they do.

Radical proposals have been made by the British government in an effort to bring under control the rapidly escalating cost to the taxpayer of socially funded legal services: Lord Chancellor's Department (1996). These proposals would change the nature of the contract under which law firms are reimbursed for work they do on behalf of clients whose legal expenses are met through government subsidy. Public reaction to the proposals has been comparatively muted but, as we will show below, the implications for the consumer could be substantial.

\subsection{Private insurance}

The market for LEI is well developed in a number of European countries, but not so much in the UK (see Rickman and Gray, 1995). The method of provision of legal services to insureds under these policies has some similarities with provision in the social insurance sector, but it is by no means uniform. An important development in the British market over recent years is that (private) insurers have come to take a much more active role in seeking to control the costs of meeting claims under LEI policies.

The private market for LEI, which began life only comparatively recently in the UK, experienced a trough of poor profitability in the early 1990's but appears now to be recovering. The response to the collapse of profitability took a variety of forms. Insurers have moved in some cases to a degree of vertical integration. In-house personnel may be used for some proportion of the more routine provision of legal services to insureds, as they are to a high degree in countries such as Holland, with more specialist cases being sent out to specialist law firms. As an alternative to developing their own capacity to deliver legal services, other insurers have moved in the direction of developing tighter control over the law firms providing them with services. This tightening takes various forms, ranging from closer monitoring of the amount and quality of inputs a law services contracting partner is delivering through to the incorporation of incentives into supply contracts for cost containment.

It seems likely that this crisis in the private sector of the market was precipitated in part by similar sorts of agency issues to those which have contributed to the crisis in the public sector. The response of insurers in the private market has been more pragmatic and gradual than what is proposed for the social insurance sector, and it remains to be seen whether this more measured approach will be more effective than the root-and-branch approach of the government.

In a later section of the paper we compare these developments in the private insurance market with the recent government proposals for reforming the terms of service supply contracts in the social insurance segment of the market. Before doing that, 
however, we consider developing a more general framework within which the alternatives can be analyzed.

\section{Analytical framework}

There are a number of areas in economics in which have emerged issues with a similar structure to those referred to in our brief review of the UK's current arrangements for financing the provision of legal services. The essence of the structure with which we are concerned here can be characterized as a three-way relationship between groups with an interest in the provision of goods or services. One party, the provider, supplies legal services (or goods or whatever) to a second party, the client, and receives reimbursement from a third party, the reimburser, in our case the private or social insurer. In their book "A Theory of Incentives and Procurement and Regulation" Laffont and Tirole (1993) develop a framework which can be applied very naturally to problems with this kind of structure. On the Laffont and Tirole approach the problem is for the reimbursing party to construct a contract with the service provider so as to resolve as many as possible of the agency, moral hazard and adverse selection problems which inevitably attend these threeway relationships.

\section{Fig. 1: The lawyer-client-insurer nexus of contracts}

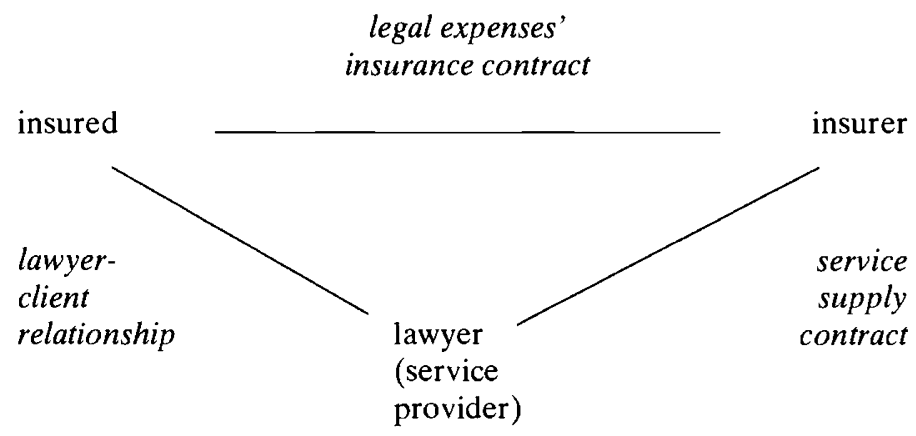

Figure 1 illustrates a convenient schematic way of summarizing the nexus of contracts at issue in a legal expenses context. Asymmetries of information are likely to be endemic in such a setting. The insurer has imperfect information about the work being done by the law firm and about the insured's preferences and riskiness. The lawyer has imperfect information about the insured's position. The client has imperfect information about the work being done on her behalf by the lawyer. The reimbursing party (the insurer) has to anticipate the strategic behaviour these asymmetries of information are likely to prompt in the contracts the insurer agrees with both the service provider and the insured. A particularly acute form of informational asymmetry is inclined to arise in the legal services setting if the lawyer has a "cost-plus" type of contract with the insurer and the client is fully insured. Unless some sort of control is built into the contract, there is a significant danger that the lawyer and the client will collude against the insurer, since both the client and the lawyer may see it as being in their interest to invest more legal inputs in a case than the insurer would wish or would be efficient. 
Since it is the insurer who is the driving force in the model, the insurer is the principal who is seeking to maximize either profits (private insurer) or social welfare (social insurer) by means of an appropriate pair of contracts with the client (via an insurance contract) and with the lawyer, who is the agent (via a service supply contract). We now consider the three sets of relationships in more detail.

\subsection{The professional-client relationship}

We begin by developing a model intended to illustrate the relationship between the professional and her client. Unlike health services, in which a sick patient seeks treatment from a single doctor, legal services are very often used by two sides to a dispute. There are the equivalent of two doctors and two patients. An important feature of the demand for legal services, at least in dispute resolution settings, is that there is interdependence between the two parties, and the payoffs to one side will be conditioned on the strategy followed by the other side. The moral hazard problems here can be acute. First, even a self-financing client employing a lawyer may know rather little about either (a) the time and effort expended by the lawyer or (b) the effectiveness of the effort: see further Emons (1997). Secondly, because of the interdependence between the parties to a claim, the lawyer may plausibly argue that further inputs are justified simply on the grounds that the other side is spending more: see further Bowles (1997). ${ }^{1}$

A client without insurance will obviously want to seek to control lawyer opportunism. Various devices have emerged to offer reassurance in such settings. Professional selfregulation (and ethical codes) and complaints procedures sponsored by governments or the legal profession are one source. The other main source is via the incentive structure of the client-lawyer contract. Contingent fee systems (or the UK system of "fee uplifts" for successful lawyers) are one method of tying lawyer remuneration to the outcome of a case, and thus indirectly to the effort expended: see further Gravelle and Waterson (1993). An alternative, apparently being increasingly used by commercial firms using legal services, is for the client to agree a fee for the case with the lawyer in advance. This gives the client greater control over spending on services, albeit by sacrificing some control over the "stopping rule" the lawyer applies in deciding how much effort to expend on the case.

For the client with insurance the story is a little bit different. If fully insured, whether through a social or a private scheme, the client has every incentive to encourage the lawyer to raise inputs on the case, since the client is fully insulated from the resulting cost pressures. The insurer can seek to control this type of opportunism through the insurance contract, and/or through the legal services provision contract, as we show in the relevant section below.

\subsection{The insurer-client relationship}

The insurer (social or private) may contemplate various types of contract before choosing which to offer. The variation in the incentive structure of the contract can usually

\footnotetext{
I There is reason to believe that the English rule for allocating legal costs (where the losing party meets the winner's costs) might exacerbate this position: the prospect of shifting costs to the other party creates an externality whereby neither party faces the full cost of extra expenditure in expectation (see Hause, 1989).
} 
be characterized in terms of the mix of premium charged and the fee, if any, the client contributes when using services covered by the insurance contract. Where the client pays some proportion of the costs of services (or a fixed contribution in the form of a deductible), the contract is said to entail some degree of "demand side cost sharing": see further Ellis and McGuire (1993) and the discussion in sections 4 and 5 below. The insurer may also impose a ceiling on the amount of coverage offered by the policy. The social insurer will, in general, be more tightly constrained in designing contracts than the private insurer. Particularly in the area of criminal law, or in cases where a citizen faces the threat of imprisonment, the government will often be constitutionally bound to provide (full) funding for services.

Control will usually be exercised by the insurer over client eligibility for services. In the case of private sector insurers this may be manifest in excluding certain kinds of legal action from coverage (e.g. matrimonial cases). In the case of social insurers, coverage may be limited to citizens who can satisfy something like the Legal Aid system's "legal merits" test, which seeks to screen out weak cases.

\subsection{The insurer-provider relationship}

It is the relationship between the insurer and provider where scrutiny seems to have been concentrated in recent years and where the most radical developments are being contemplated. A key distinction is drawn in the incentive contracting debate between high-powered and low-powered incentive contracts, and this is a distinction which very neatly encapsulates part of the debate about the relationship between insurer and service provider. From the insurer's perspective the objective will, in essence, be the minimization of the cost of meeting claims for the provision of legal services. A low powered contract, where the insurer instructs the lawyer to provide services and to submit a reimbursement claim after the event, leaves the insurer open to lawyer opportunism. The lawyer may do "too much" work on the case, may produce an inflated account of the costs incurred or may exaggerate the amount of work done. Asymmetric information arises here since it will be costly for the insurer to monitor closely either (a) the lawyer's choice of effort level or (b) the degree to which the effort level chosen is an appropriate one.

A high powered incentive contract, under which the lawyer agrees a fixed sum in advance to handle a case opens up the client to lawyer opportunism. The lawyer can no longer pass on costs at the margin to the insurer: additional costs reduce profits one for one. Behind the barrier of asymmetric information the lawyer this time will tend to do "too little" work on the case. The monitoring problem this time falls, at least in part, to the client since the insurer can simply argue that they have met their side of the insurance contract by providing services. The client will have to demonstrate that the quality of service received has been inadequate. In practice, of course, clients will look for ways of minimizing their exposure to such risks. The reputation of insurers for providing good quality services will cause the insurers to seek ways of imposing quality standards on the lawyers with whom they contract.

A second important observation about the insurer-provider relationship is that it is likely to entail only a rather limited amount of idiosyncratic investment by the two sides. Law firms are not highly capital intensive, and such capital as they do use is rarely tied to 
the interests of a particular client. In principle this should limit the scope for provider opportunism: Williamson (1979). But this "advantage" for the insurer may be offset by the substantial informational asymmetry which besets any user of professional services. This may reawaken the argument that the insurer may wish to contemplate either some degree of vertical integration with the lawyer or may engage in some form of relational contracting in an effort to reduce quality monitoring costs.

\section{UK developments}

The above framework can be applied to developments in the UK in a comparatively straightforward way.

\subsection{The UK's LEI market}

The evolution of the private LEI market in the UK suggests that the insurers have adapted their behaviour towards service providers in rather the way section 3 implies. By moving away from a "spot" market, low powered incentive contract approach towards a high powered relational contract approach, the private sector insurers seem to have found a means of controlling lawyer opportunism. Alongside this development they have also engaged in a degree of vertical integration by employing their own in-house lawyers. It seems likely that these in-house lawyers play the twin role of both handling some of the simpler sorts of cases but also of monitoring the actions and costs of law firms with whom they contract for provision of more specialist services.

In other European countries, it seems that comparable forms of vertical integration have already occurred in the private sector. In Holland, for example, where the LEI market is substantially more developed than in the UK, insurers have comparatively large in-house legal capacity which is used both for giving advice and also for acting in court.

\subsection{The Legal Aid debate}

From the start of the Legal Aid scheme in 1947, the government procured legal services through what amounted to "spot market" purchases. It has traditionally relied on a low powered incentive approach, using a fee for service remuneration scheme under which the law firm chooses the level of inputs in a case and is then reimbursed according to a complex schedule of hourly fees and specific task-based fees. The system has worked on

a demand-driven case-by-case basis which has made effective control of aggregate spending impossible to achieve: see Bowles (1997), Dnes and Rickman (1997) and Hope (1996).

The ease with which the government was able to secure services depended, in essence, on the strength of demand for legal services in other sectors of the market. When demand elsewhere was buoyant, as in the period following financial deregulation which caused a substantial boom in the property market and created excess demand for legal services, the opportunity cost of services in many law firms overtook the fees offered for Legal Aid work, and reduced the willingness of firms to supply. But during the contraction which followed in the late 80's and early 90's many law firms found Legal Aid work to 
have become profitable once more. The consequence was a very sharp rise in the real cost of the scheme.

It was largely in response to this cost escalation that steps were taken to try to impose some greater degree of control over expenditure. The first significant step in the revision of the structure of the government's contracts with law firms for the provision of legal services, was the development of a system of "franchising". This system, in operation since 1993, allows law firms to apply for a franchise from the Legal Aid Board, under which they take on certain administrative tasks, in return for several financial benefits such as lumpsum payment on account when legal aid is granted. Franchising gives the Legal Aid Board some control over franchisees because the latter need to satisfy quality checks in order to retain their franchise; something they may be keen to do in order to attract legal aid work.

The second, and in many ways more fundamental shift, is the proposal to move to a system of "bulk contracts". The Lord Chancellor's Department has proposed a comparatively high-powered incentive scheme under which it would agree contracts for the supply of services for a fixed period at a fixed price. The price would be fixed through a tendering or auction process in which firms would be invited to make bids for the supply of services. An upper and lower bound on the volume of cases to be supplied would probably be specified, so that the firm making a price bid would be able to estimate upper and lower bounds on the revenue they could expect to earn. Such a scheme would clearly have substantial implications since cost-saving initiatives become profitable for the firm.

The motivation of the proposals is, in essence, to bring expenditure on legal services under control. Ultimately it is the adoption of a high-powered incentive contract which will address the moral hazard on the lawyer's part. It is this move which has the critical merits of eliminating in large part the need for observing or auditing how the firms behave. It is also a way of limiting the incentive to collude with the client in the inflation of the volume of services used.

There remain unresolved issues with the bulk contract proposals. The "cherry picking" problem is likely to be acute, with law firms choosing wherever they can to take only the cheapest cases. Promises of safeguards to prevent this occurring are not at present entirely credible. The bidding process for contracts is likewise somewhat problematic. In areas where the market is rather thin (e.g. in rural markets) there may be a shortage of bidders and the possibility of collusion between bidders is clearly present. The scheme is interpreted by Dnes and Rickman (1997) as a means of defending the public purse from private sector opportunism.

In addition to an overhaul of the structure of the contract between the Legal Aid Board and the lawyer, it seems that the government is pursuing other lines of reform. One element is the possibility of introducing an advice-line scheme similar to that which has developed rapidly in the private sector. This is a form of vertical integration, since it would entail employing solicitors or legal executives to give advice directly to citizens rather than subsidizing the provision of such advice through private law firms. It does, however, stop short of the degree of vertical integration implicit in public defender type schemes where lawyers are employed on salaried contracts by government agencies to provide legal services to citizens qualifying for subsidized legal services. 
One reason for limiting the degree of integration within the public sector is that public provision is increasingly viewed as encouraging high costs and inflexibility. A second reason is that public provision, as distinct from public subsidy of private provision, is perceived to offer the citizen less assurance in terms of its independence from government.

In the area of the provision of legal services there may be constitutional constraints requiring that citizens be provided access to adequate legal representation. As well as encouraging provision of services through the private rather than the public sector, these constitutional safeguards will always tend to make it particularly difficult to implement spending controls.

\section{Health care parallels}

It is not only in the legal services area that insurers have to confront the issues we have been discussing here. In terms of the analytical structure of the three-way relationships we have been describing there are clear parallels with health care provision on both sides of the Atlantic. As a result, it is instructive to consider the literature which has developed to analyze the regulatory and contractual issues in this context. In both the US and the UK, health care is purchased by a third party (an insurer or similar), supplied by a professional practitioner on behalf of a patient (or "client"). This parallels very closely the legal setting we have described, which involves relationships between a third party payer, a lawyer and a client. The situation in the US health care market resembles the LEI setting in that the third party payer is a private insurer or Health Maintenance Organization. In the UK, the health care parallel is slightly different since most health care is paid for by the publicly funded National Health Service. It still has close parallels, however, particularly since the creation of a distinction between "fundholders" and "service providers" within the 'internal market' of the NHS. The purpose of this bifurcation has been to create an incentive structure to help "discipline" providers. The analytical issues are similar across the settings: how can the purchaser control her exposure to costs while maintaining quality on behalf of a poorly informed "client"?

\subsection{Health care models}

Ellis and McGuire (1986) consider this problem in a model where a physician, employed by a hospital, provides services to a passive client. The physician is selfinterested to the extent that he is concerned about hospital surplus, but also altruistic in so far as he also cares about the benefits received by the patient from treatment. A third party reimburses the hospital for the costs of treatment. Ellis and McGuire contrast the treatment level under full cost-reimbursement with that under prospective payment. They discover that the former leads to an oversupply of services to the patient while the latter leads to an undersupply. The reason is that a passive patient does not question the treatment level she is receiving so there is no cost to raising this level when the reimburser stands ready to fund it all, but these incentives are altered when a fixed fee per treatment is paid. This is the distinction between low-powered and high-powered incentives described earlier. Ellis and McGuire show that a degree of cost sharing, between the reimburser and hospital, provides the appropriate incentives for treatment: the hospital is 
reimbursed a (linear) fraction of its costs, thereby causing the physician to internalize the cost externalities of treatment decisions. ${ }^{2}$

Since Ellis and McGuire's paper, a number of authors have found prospective payment to outperform cost-reimbursement and, often, cost-sharing. Two key assumptions are required here: the physician has to choose both quality of treatment and the quantity of cost-reducing effort he puts into a case and patient demand for treatment must be based on accurate rankings of true quality (even though they may be unable to perceive exactly what quality is being supplied). Under these circumstances, Ma (1994) and Chalkley and Malcomson (1995a) find that prospective payment can solve the reimburser's problem of inducing optimal quality and effort. Of course the introduction of beneficial cost-reducing effort makes it intuitive that prospective payment should form part of the reimbursement package: a fixed cost per case means that the physician/hospital retains any surplus on the contract. Further, however, with patient demand responding to quality, hospital revenue also depends on attracting patients. In this context, therefore, an appropriate level of prospective payment induces optimal quality so that enough patients can be attracted: the combination of quality-sensitive patient demand and prospective payment solves the reimburser's problem. Ma shows that a role for cost-reimbursement returns as the hospital is allowed to turn away ("dump") high-cost-patients or seek low-cost ones ("creamskimming"). Now, cost-reimbursement for high-cost cases is beneficial, although Sharma (1996) notes that this may damage the hospital's own incentives for cost-reduction.

Difficulties arise with this result, however. Within the model itself, Chalkley and Malcomson (1995a) demonstrate that prospective payment needs modification when the optimal outcome is not demand-constrained (since at the margin, demand can no longer influence quality choice). They also show that their results do not hold in general when quality is multi-dimensional: the combined instruments of demand and price per case cannot achieve all of the first best quality levels. ${ }^{3}$ Further, in another paper, Chalkley and Malcomson (1995b) examine the effects of quality-insensitive patient demand; an assumption which may be reasonable in health and legal services, where "clients" may have too little information to distinguish quality levels. They distinguish different provider motivations, beginning with a self-interested provider. Here, it is not possible for the reimburser to induce first best quality and effort and the choice of contract depends on which of these it values more highly. To achieve optimal quality, cost reimbursement is appropriate, whereas prospective payment forces optimal cost-reducing effort. If the provider is constrained from borrowing to cover losses, a cost-and-volume contract (where the price per patient is a function of the number treated) achieves first best. When the provider is fully benevolent (and assumes the purchaser's benefit function), the first best effort and quality can be achieved by a block contract (a lump-sum of money). In this case, the provider will use the money in exactly the way that the purchaser would wish. Of

\footnotetext{
${ }^{2}$ Ellis and McGuire (1990) extend this analysis to a situation where the patient is forced to monitor treatment intensities by facing insurance co-payments. "Supply-side cost sharing" still emerges as optimal. More recently, McGuire and Rickman (1996) look at the physician's decision when he can also treat the patient privately. Again supply-side cost sharing (now possibly non-linear) achieves optimal publicly funded service levels but cannot generally induce optimal privately funded care. See Newhouse (1996) and Ellis and McGuire (1993) for surveys.

${ }^{3}$ The result is similar to Tinbergen's (1952), which is also how McGuire and Rickman (1996) interpret their results.
} 
course, if the provider's borrowing ability is restricted, such a contract may mean untreated patients in periods of unexpectedly high demand. ${ }^{4}$ Finally, when the provider is partially benevolent, the appropriate contract combines prospective payment and costreimbursement (i.e. supply-side cost sharing): as with $\mathrm{Ma}$, in the presence of dumping and cream-skimming, at the margin it is optimal to trade-off cost-reducing effort for quality, given that the provider has some natural inclination to produce these anyway. Of course, this result itself depends on the costs of monitoring production costs not being prohibitive.

\subsection{Implications for legal aid and LEI contracts}

Our discussion of health care parallels has several implications for the contracts between legal purchasers and providers we discussed earlier. The first is that the nature of the contract should depend on the circumstances involved: flexibility in contracting is clearly desirable. The second implication is that, on initial inspection, it appears that first best outcomes can be achieved by choosing the appropriate contract. However, the circumstances required might actually be difficult to fulfill in the legal context (as well as the health one). In particular, optimality can be achieved when demand responds to (onedimensional) levels of service quality, when there is no need for cost-reducing effort and/or when the provider is fully benevolent. In the circumstances where cost-reducing effort matters, prospective payment features prominently in the optimal contract. However, in circumstances which could easily characterize the legal setting (potential for dumping, cream-skimming and partially benevolent providers), an element of cost reimbursement and/or cost-sharing becomes important.

Given these implications, it is interesting to note that the proposals for legal aid contracts (Lord Chancellor's Department, 1996) assume (full) prospective payment. Our discussion in this section suggests that this will be problematic unless quality monitoring is effective and decisions on cases are monitored. Otherwise, there is an obvious concern that cost containment will be achieved at the expense of service quality. It is also interesting to note that the introduction of conditional fees into the legal services market in England and Wales has stimulated a form of cost-sharing between insurers (purchasers) and lawyers (providers). This has taken the form of "after-the-event" LEI which offers policies once an actionable event has occurred. As a result, the conditional fee lawyer effectively insures own client costs in the event of losing the case while the insurer insures inter partes costs. In the case of the former, this is particularly appropriate because the lawyer takes own cost decisions and therefore bears reasonably controllable risks. The latter leaves the insurer exposed to the opponent's actions but, at least, without also having to monitor own client costs. Lord Woolf's (1996) proposals for fixed recoverable inter partes costs would further assist insurers in this respect.

\section{Conclusion}

There are several stakeholders in a legal action. As well as the two parties in a (noncriminal) dispute there are the lawyers acting for both sides and there may also be insurers involved on both sides as well. Economic models of legal disputes have made allowance

\footnotetext{
${ }^{4}$ Fenn, Rickman and McGuire (1994) also explore the implications for demand uncertainty for contracts between purchasers and providers of health care.
} 
for cost-shifting rules and some other complications, but have not paid so much explicit attention to the impact of insurance on the conduct of cases. Gravelle and Waterson (1993) for example in their discussion of contingent fees focus on the possible conflict of interest between an income maximizing lawyer and a client wishing to maximize her net recovery of damages from a personal injury action. They note that critics of contingent fees, including the professional bodies, feel that lawyers' ethical standards may not be strong enough for them to resist the pressures created by contingent fees.

Our argument in this paper has been that lawyers have to consider not only their own interests and those of their clients, but also the wishes of an insurer underwriting the costs of the client. The degree to which the interests of the insurer will act as a constraint on lawyer behaviour will, in our view, depend upon the structure of the contract between the insurer and the lawyer. Under a low-powered incentive contract, such as the existing arrangements for Legal Aid, the lawyer's interests coincide with those of the client: both will want to spend "too much" on the claim. Under higher powered incentive contracts, such as the bulk contract scheme the Lord Chancellor's Department proposes to introduce, the lawyer will want to spend "too little" on the claim. For the lawyer, collusion with the client against the insurer is no longer optimal. Rather it is collusion between the lawyer and the insurer against the client which becomes optimal: the lawyer's interests become aligned with those of the insurer.

Within the Legal Expenses Insurance market, it seems that UK insurers learned this lesson the hard way during the early part of the 1990's when they experienced significant losses. One might speculate that the "tightening up of case management" which apparently occurred subsequently was effected primarily by increasing the power of the incentive contracts insurers had with law firms. By moving away from the "cost-plus" contracts of the kind lawyers have been accustomed to offer towards the "fixed fee" type contracts which deal more successfully with agency costs, we infer that insurers have restored profitability to this market sector.

One implication of this is that should the LEI market expand beyond its current rather small scale and become genuinely competitive, then insurers will be driven to write policies which match the demands of consumers. In order to maximize profits, insurers will need to strike the right balance in their contracts with lawyers between the control of agency costs and the provision of legal services of an appropriate quality. Whether this can be best achieved through some degree of vertical integration (direct hiring of their own legal staff) or through manipulation of the terms in supply contracts with law firms remains to be seen.

In the social insurance sector within the UK, the Lord Chancellor's Department seems to have opted for a radical solution to the its expenditure control problem. Rather than take the evolutionary path, as insurers in the private sector have done, the LCD is proposing a revolutionary approach its relationship with law firms. In the light of findings from models developed for the health care market, where many similar issues arise, it seems quite likely that the optimal solution will not be achieved by an overnight change from very low to very high powered contracts. The LCD has not found it easy in the past to control the quality of service provision, and a move to high powered contracts will only increase the importance of monitoring case selection bias and the quality of service provided to clients. 


\section{REFERENCES}

BOWLES, R., 1997; Reform of Legal Aid and the Solicitors' Profession, Hume Papers in Public Policy, 4(4), pp. 4-23.

CHALKLEY, M. \& MALCOMSON, J. M. (1995a); Contracting for Health Services with Unmonitored Quality, Discussion Papers in Economics and Econometrics, 9510, University of Southampton.

CHALKLEY, M \& MALCOMSON J.M. (1995b); Contracting for Health Services when Patient Demand Does Not Reflect Quality, Discussion Papers in Economics and Econometrics, 9514, University of Southampton.

COOTER, R. D. \& RUBINFELD, D. L. (1989); Economic Analysis of Legal Disputes and their Resolution, Journal of Economic Literature, 27, pp. 1067-1097.

DNES, A. \& RICKMAN, N. (1997); Contracts for Legal Aid: A Critical Discussion of Government Policy Proposals, European Journal of Law and Economics (forthcoming).

EMONS, W. (1997); Credence Goods and Fraudulent Experts, RAND Journal of Economics, forthcoming.

ELLIS, R. P. \& MCGUIRE, T. G. (1986); Provider Behaviour Under Prospective Reimbursement: Cost Sharing and Supply, Journal of Health Economics, 5, 129-151.

ELLIS, R. P. \& MCGUIRE, T. G. (1990); Optimal Payment Systems for Health Services, Journal of Health Economics, 9, 375-396.

ELLIS, R. P. \& MCGUIRE, T. G. (1993); Supply-Side and Demand-Side Cost Sharing in Health Care, Journal of Economic Perspectives, 7, 135-151.

FENN, P., RICKMAN N. \& MCGUIRE, A. (1994); Contracts and Supply Assurance in the UK Health Care Market, Journal of Health Economics, 13, 125-144.

GRAVELlE, H. \& WATERSON, M. (1993); No Win, No Fee: Some Economics of Contingent Legal Fees, Economic Journal, 103, 1205-1220.

HAUSE, J. (1989); Indemnity, Settlement and Litigation, or I'll be Suing You, Journal of Legal Studies, 18, 157-179.

HOPE, M. (1996); Expenditure on Legal Services, mimeo, Lord Chancellor's Department, 1996.

Insurance Trends (1997); Legal Expenses Insurance, Insurance Trends, 12, January 1997, 10-17.

LAFFONT, J-J. \& TIROLE, J. (1993); A Theory of Incentives in Procurement and Regulation, The MIT Press, London.

MA C. A. (1994); Health Care Payment Systems: Cost and Quality Incentives, Journal of Economics and Management Strategy, 3, 93-112.

MCGUIRE, A. \& RICKMAN, N. (1996); Regulating Provider Reimbursement in a Mixed Market for Health Care, Paper presented at the International Health Economics Association conference, Vancouver, May 1996; mimeo, University of Surrey.

NEWHOUSE, J. P. (1996); Reimbursing Health Plans and Health Providers: Selection versus Efficiency in Production, Journal of Economic Literature, 34, 1236-1263.

RICKMAN, N. \& GRAY, A. (1995); Legal Expenses: State Legal Aid and the Market for Legal Expenses Insurance, in Risk, Insurance and Welfare: The Changing Balance between Public and Private Protection, Association of British Insurers, London.

SHARMA, R. (1996); Prospective Payments and Cost Reimbursement in Health Care: Cost Incentives Revisited, Working Paper 95-96-14, Department of Economics, University of Florida. 
SKORDAKI, E. \& WALKER D. (1994); Regulating and Charging for Legal Services: An International Comparison, The Law Society, London, Research Study no. 12.

TINBERGEN, J. (1952); On the Theory of Optimal Policy, North Holland, Amsterdam.

WILliAMSON, O. E. (1979); The Governance of Contractual Relations, Journal of Law and Economics, 22, 233-61.

WOOLF LORD, H. (1996); Access to Justice: Final Report, London, HMSO. 